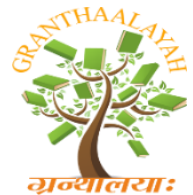

\author{
INTERNATIONAL JOURNAL OF R
GRANTHAALAYAH \\ A knowledge Repository
}

Science

\title{
COMPARISON OF THREE DIFFERENT TECHNIQUES FOR ISOLATION OF NEUTROPHILS FROM BLOOD AND THEIR UTILITY IN PERFORMING NITROBLUE TETRAZOLIUM TEST
}

\author{
Dr. Shivanand S. Pattan ${ }^{1}$, Dr. Kishore G. Bhat ${ }^{* 2}$, Mrs. Geeta D. Pattar ${ }^{2}$, Mrs. Manjula \\ Kuntagi ${ }^{2}$ \\ ${ }^{1}$ Department of Physiology, Maratha Mandal's NGH Institute of Dental Sciences and Research \\ Centre, Bauxite Road, Belgaum, India \\ ${ }^{2}$ Department of Microbiology, Central Research Laboratory, Maratha Mandal's NGH Institute of \\ Dental Sciences and Research Centre, Belgaum, India
}

\begin{abstract}
Background \& Objectives: Assays for neutrophils constitute an important component of screening tests in clinical immunology. There are no standard protocols for performing many of these tests and procedures vary from one laboratory to another. In addition, normal ranges for these assays in healthy Indian population have not been defined. Hence, an attempt is made to evaluate and present a simple technique for WBC isolation and NBT test.

Methods: The study involved participation of 30 healthy adult volunteers. Ten of blood sample collected from each subject was subjected to three different procedures for isolation of WBCs Ficoll-Hypaque gradient, dextran sedimentation and gelatin sedimentation methods. Cells isolated from these procedures were then used to perform NBT test. Smears were prepared, stained with Giemsa and results were expressed as \% of stimulated and unstimulated cells.

Results: The mean cell yield from both dextran and gelatin methods was comparable (2921.67cells vs 2806.67cells/cu mm). The cell yield from Ficoll-Hypaque method was much lower (1408.33 cells/cu mm). In NBT test, the mean readings of stimulated (61\%) and unstimulated cells (18\%) were almost similar in all three procedures of cell isolation.

Conclusions: Comparison of procedures show that gelatin and dextran sedimentation methods yield high amount of relatively purified WBCs. The efficacy of cells isolated from all three procedures in NBT test was almost similar. The range of stimulated and unstimualted cells in the subjects were within expected levels. Gelatin sedimentation is economical, easy to perform and can be adopted to any clinical laboratory for WBC isolation.
\end{abstract}

Keywords: Dextran; Ficoll-Hypaque; Formazon; Gelatin; NBT; Neutrophils.

Cite This Article: Dr. Shivanand S. Pattan, Dr. Kishore G. Bhat, Mrs. Geeta D. Pattar, and Mrs. Manjula Kuntagi. (2019). "COMPARISON OF THREE DIFFERENT TECHNIQUES FOR ISOLATION OF NEUTROPHILS FROM BLOOD AND THEIR UTILITY IN PERFORMING 
NITROBLUE TETRAZOLIUM TEST." International Journal of Research Granthaalayah, 7(12), 115-122. https://doi.org/10.29121/granthaalayah.v7.i12.2019.305.

\section{Introduction}

Neutrophils, the most abundant of granulocytes in the blood are the major players in the host defense against invading microorganisms, especially bacteria and fungi. The primary function of neutrophils is phagocytosis and subsequent killing of microbes, which they perform using the contents of large number of granules present in their cytoplasm. In addition, these cells also perform a diverse range of cellular functions. Abnormalities in these functions severely compromise host defenses leading to recurrent bacterial and fungal infections (1). Hence to identify these specific deficiencies in neutrophil function, a series of assays have been developed that can be performed in the laboratory.

To perform the neutrophil function tests in the laboratory, isolation of these cells in a relatively pure form from other blood components is of utmost importance. Most neutrophil isolation protocols exploit the differences in cell density of various blood cells as the basis for separation. Some of these methods include use of Ficoll-Hypaque, discontinuous gradient of plasma / percoll and high molecular weight dextran $(1,2)$. Another method of cell separation that has not been evaluated properly for neutrophil separation is use of gelatin solution (3). However, not many attempts have been made to compare the efficacy of these various isolation protocols and their influence on the results of neutrophil function tests from human blood.

One of the most common screening tests performed to assess the release of reactive oxygen intermediates that ultimately lead to intracellular killing is nitroblue tetrazolium (NBT) assay (4) which is technically simple and easy to interpret.

In the present study, an attempt has been made to compare the efficacy of three different neutrophil isolation protocols - Ficoll-Hypaque, dextran sedimentation and gelatin sedimentation methods and the performance of isolated cells in NBT assay in healthy individuals. This investigation is part of the study titled "Phagocytic function tests; establishing guidelines and defining normal levels in blood and saliva of healthy adult subjects" funded by RGUHS, Bengaluru.

\section{Materials and Methods}

The present study comprised of 30 healthy adults belonging to both the sexes between the age range of 25 and 50 years. Subjects who were smokers and/or alcoholics, those suffering from diabetes mellitus and any other chronic illness were excluded from the study. Complete blood count was performed on all individuals and only those with normal total and differential white blood cell count were enrolled for the study. Approval from Institutional Ethics Committee was sought before initiation of the study. A written informed consent was obtained from each participant before collection of blood sample.

A volume of $10 \mathrm{ml}$ blood was collected from each subject in two vacutainers containing EDTA as anticoagulant. All samples were processed on the same day of collection. Each blood sample was subjected to three different methods of cell separation: Ficoll-Hypaque method for neutrophil 
separation and Dextran and gelatin sedimentation methods for WBC separation. The total yield of cells from each procedure was calculated and compared. In addition, NBT test was performed on cells obtained from each procedure to test their efficacy. The procedures adopted were briefly as follows.

Each blood sample was diluted with equal quantity of Hank's Balanced Salt Solution (HBSS) and was used for further processing on WBC/neutrophil separation.

Gelatin Method: Three ml of diluted blood was mixed with 2 volumes of gelatin $0.5 \%$ (w/v, prepared in $0.9 \% \mathrm{Nacl}$ ), mixed properly and incubated at room temperature for 45 minutes. The cell rich supernatent was then transferred to another tube and centrifuged at $1500 \mathrm{rpm}$ for 5 minutes to get the cell pellet. This was washed with sterile PBS ( $\mathrm{pH} 7.2)$ three times to remove traces of gelatin. The presence of WBCs in the preparation was confirmed by microscopy (5).

Ficoll-Hypaque Method: Three $\mathrm{ml}$ of Ficoll-Hypaque was transferred to a $15 \mathrm{ml}$ centrifuge tube and was gently layered with equal volume of diluted blood taking care not to mix the two solutions. this was centrifuged at $1500 \mathrm{rpm}$ for 30 minutes. The components will then be separated in a series of layers. The top most portion contains HBSS and plasma and was discarded. This was followed by a thin ring of opacity which contains lymphocytes and monocytes. The layer beneath this contains Ficoll-Hypaque which was discarded. All the red cells form a pellet at the bottom over which there would be a thin ring of granulocytes. this portion was transferred to another tube and centrifuged to get a pellet and was washed three times with PBS as mentioned earlier.

Dextran Sedimentation: Three $\mathrm{ml}$ of diluted blood was mixed with equal volume of $3 \%$ dextran (mol wt 150,000 w/v in $0.9 \% \mathrm{Nacl}$ ). The suspension was mixed and allowed to stand for 30 minutes at room temperature. The supernatent was removed carefully into another tube and was centrifuged and washed as mentioned earlier (6).

The total cell yield was calculated from the preparations of all the three procedures mentioned above by using Neubauer's counting chamber and expressed as cells/cu mm. The total cell count was then adjusted to a concentration of 1x105 cells in HBSS before proceeding with NBT test.

NBT Test: One hundred ul of WBC suspension was mixed with $100 \mathrm{ul}$ of NBT $(0.3 \% \mathrm{w} / \mathrm{v}$ in $0.34 \%$ sucrose in dist water), 100ul of endotoxin (prepared from Esch. coli) and 100ul of HBSS medium. A second tube of unstimulated cells also was set up for each sample where endotoxin was replaced with additional 100ul of medium. The tubes were incubated for $20 \mathrm{mins}$ at 37c followed by 20 mins at room temperature. The suspensions were then mixed, smears were prepared, fixed with alcohol and stained with Giemsa stain for 5 minutes. A total of 200 neutrophils were counted and the number of stimulated and unstimulated cells were noted and expressed as percentage. The stimulated cells show the presence of bluish black formazan granules in their cytoplasm (Fig 1). 


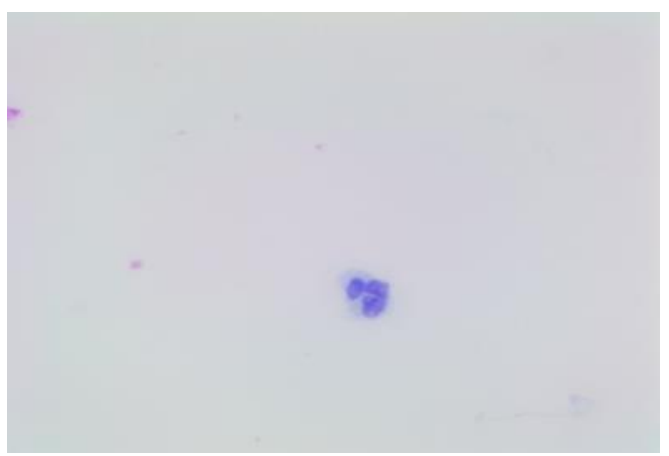

Figure 1: A. Normal Neutrophil

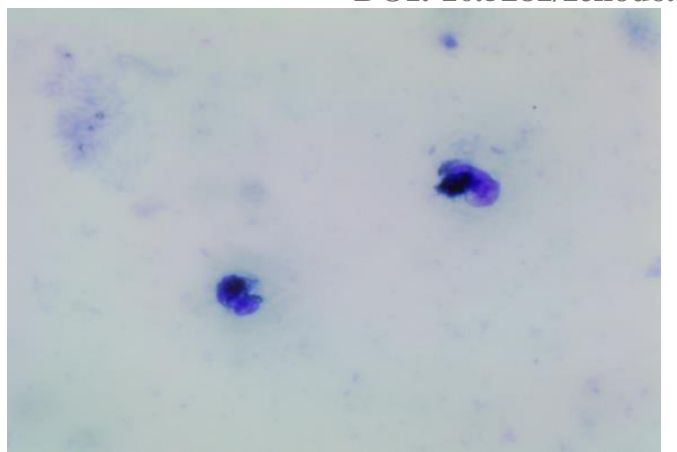

B. Neutrophils with formazan granules

\section{Results and Discussions}

Cell yield: A mean of total cells recovered from each procedure was calculated (Figure 2). The mean cell yield from dextran sedimentation was 2921.67cells/cu mm (range 2000 - 3500, SD 443). This was comparable to the readings shown for gelatin sedimentation which was $2806.67 \mathrm{cells} / \mathrm{cu}$ $\mathrm{mm}$ (range 1800-3600, SD 585.86). However, the cell yield by Ficoll-Hypaque method was much lower with a mean of 1408.33 cells/cu mm (range 900 - 2650, SD 346.43). When the results from individual samples were compared, there was variation in cell yield with different procedures in some samples (Table 1).

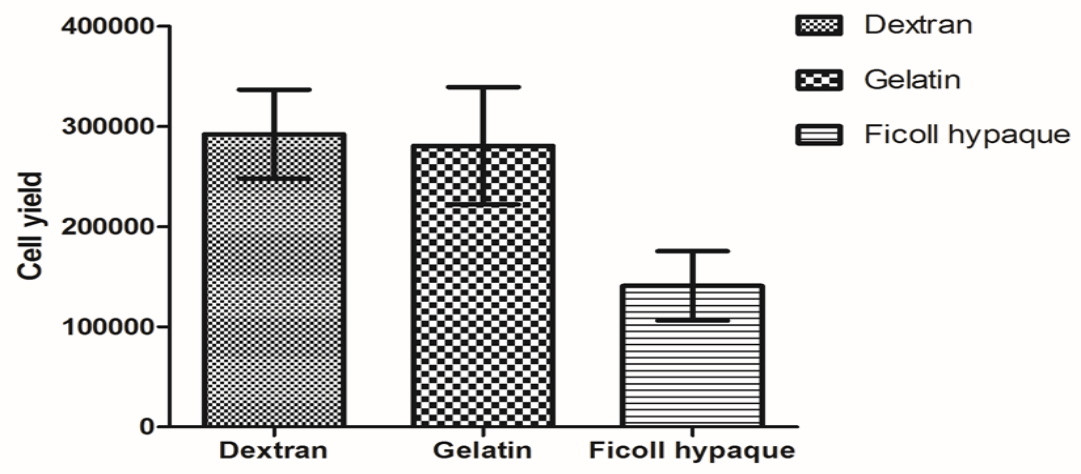

Figure 2: Showing Total Cell Yield in Dextron, Gelatin and Ficoll hypaque

Table 1: showing the cell yield and NBT results for individual samples for all three methods of cell separation.

\begin{tabular}{|l|c|c|c|c|c|c|c|c|c|}
\hline \multirow{2}{*}{ Sample No. } & \multicolumn{3}{|c|}{ Dextrane 3\% } & \multicolumn{3}{c|}{ Getatin 0.5\% } & \multicolumn{3}{c|}{ Ficoll Hypaque } \\
\cline { 2 - 10 } & $\begin{array}{c}\text { NBT } \\
\text { Control }\end{array}$ & $\begin{array}{c}\text { NBT } \\
\text { Test }\end{array}$ & $\begin{array}{c}\text { Cell } \\
\text { Yield }\end{array}$ & $\begin{array}{c}\text { NBT } \\
\text { Control }\end{array}$ & $\begin{array}{c}\text { NBT } \\
\text { Test }\end{array}$ & $\begin{array}{c}\text { Cell } \\
\text { Yield }\end{array}$ & $\begin{array}{c}\text { NBT } \\
\text { Control }\end{array}$ & $\begin{array}{c}\text { NBT } \\
\text { Test }\end{array}$ & $\begin{array}{c}\text { Cell } \\
\text { Yield }\end{array}$ \\
\hline 1 & $18 \%$ & $70 \%$ & 220000 & $16 \%$ & $65 \%$ & 180000 & $23 \%$ & $76 \%$ & 200000 \\
\hline 2 & $15 \%$ & $67 \%$ & 270000 & $14 \%$ & $62 \%$ & 130000 & $12 \%$ & $86 \%$ & 265000 \\
\hline 4 & $16 \%$ & $76 \%$ & 240000 & $18 \%$ & $78 \%$ & 220000 & $16 \%$ & $98 \%$ & 140000 \\
\hline 5 & $15 \%$ & $53 \%$ & 300000 & $12 \%$ & $65 \%$ & 230000 & $14 \%$ & $76 \%$ & 165000 \\
\hline 6 & $18 \%$ & $63 \%$ & 230000 & $18 \%$ & $58 \%$ & 330000 & $25 \%$ & $60 \%$ & 165000 \\
\hline 7 & $17 \%$ & $45 \%$ & 200000 & $17 \%$ & $54 \%$ & 180000 & $12 \%$ & $48 \%$ & 135000 \\
\hline 8 & $22 \%$ & $60 \%$ & 200000 & $18 \%$ & $46 \%$ & 200000 & $18 \%$ & $52 \%$ & 145000 \\
\hline
\end{tabular}


DOI: 10.5281/zenodo.3595331

\begin{tabular}{|l|l|l|l|l|l|l|l|l|l|}
\hline 9 & $19 \%$ & $57 \%$ & 275000 & $16 \%$ & $58 \%$ & 295000 & $15 \%$ & $56 \%$ & 155000 \\
\hline 10 & $15 \%$ & $65 \%$ & 250000 & $13 \%$ & $73 \%$ & 275000 & $14 \%$ & $58 \%$ & 140000 \\
\hline 11 & $17 \%$ & $68 \%$ & 270000 & $20 \%$ & $62 \%$ & 255000 & $15 \%$ & $55 \%$ & 120000 \\
\hline 12 & $18 \%$ & $54 \%$ & 250000 & $17 \%$ & $65 \%$ & 235000 & $14 \%$ & $49 \%$ & 110000 \\
\hline 13 & $17 \%$ & $56 \%$ & 340000 & $14 \%$ & $59 \%$ & 255000 & $16 \%$ & $53 \%$ & 105000 \\
\hline 14 & $16 \%$ & $88 \%$ & 265000 & $18 \%$ & $82 \%$ & 265000 & $14 \%$ & $87 \%$ & 90000 \\
\hline 15 & $19 \%$ & $66 \%$ & 325000 & $20 \%$ & $69 \%$ & 350000 & $15 \%$ & $62 \%$ & 125000 \\
\hline 16 & $17 \%$ & $45 \%$ & 350000 & $16 \%$ & $52 \%$ & 340000 & $20 \%$ & $59 \%$ & 100000 \\
\hline 17 & $20 \%$ & $56 \%$ & 350000 & $17 \%$ & $52 \%$ & 360000 & $20 \%$ & $60 \%$ & 110000 \\
\hline 18 & $28 \%$ & $54 \%$ & 350000 & $26 \%$ & $48 \%$ & 290000 & $21 \%$ & $63 \%$ & 130000 \\
\hline 19 & $16 \%$ & $66 \%$ & 335000 & $19 \%$ & $62 \%$ & 300000 & $19 \%$ & $68 \%$ & 165000 \\
\hline 20 & $18 \%$ & $61 \%$ & 340000 & $21 \%$ & $56 \%$ & 380000 & $19 \%$ & $60 \%$ & 150000 \\
\hline 21 & $19 \%$ & $64 \%$ & 315000 & $17 \%$ & $67 \%$ & 300000 & $16 \%$ & $60 \%$ & 120000 \\
\hline 22 & $20 \%$ & $61 \%$ & 315000 & $17 \%$ & $58 \%$ & 300000 & $20 \%$ & $54 \%$ & 165000 \\
\hline 23 & $16 \%$ & $68 \%$ & 295000 & $19 \%$ & $69 \%$ & 275000 & $15 \%$ & $75 \%$ & 130000 \\
\hline 24 & $21 \%$ & $52 \%$ & 300000 & $17 \%$ & $54 \%$ & 330000 & $16 \%$ & $73 \%$ & 125000 \\
\hline 25 & $15 \%$ & $58 \%$ & 325000 & $16 \%$ & $55 \%$ & 325000 & $15 \%$ & $57 \%$ & 150000 \\
\hline 26 & $19 \%$ & $55 \%$ & 300000 & $17 \%$ & $49 \%$ & 290000 & $16 \%$ & $54 \%$ & 160000 \\
\hline 27 & $28 \%$ & $54 \%$ & 330000 & $26 \%$ & $54 \%$ & 280000 & $26 \%$ & $60 \%$ & 105000 \\
\hline 28 & $17 \%$ & $53 \%$ & 325000 & $17 \%$ & $53 \%$ & 350000 & $18 \%$ & $58 \%$ & 120000 \\
\hline 29 & $22 \%$ & $61 \%$ & 300000 & $19 \%$ & $59 \%$ & 285000 & $20 \%$ & $62 \%$ & 135000 \\
\hline 30 & $17 \%$ & $72 \%$ & 290000 & $19 \%$ & $75 \%$ & 285000 & $19 \%$ & $70 \%$ & 120000 \\
\hline
\end{tabular}

NBT test: The mean of unstimulated and stimulated cells from all three procedures including range and standard deviation were almost similar with minor variations (Figure 3). But when the results of individual samples were compared, there were few notable differences (Table 1). Sample numbers 1, 5, 12, 16 and 27 showed differences in the values of either stimulated or unstimulated cells among the three procedures used.

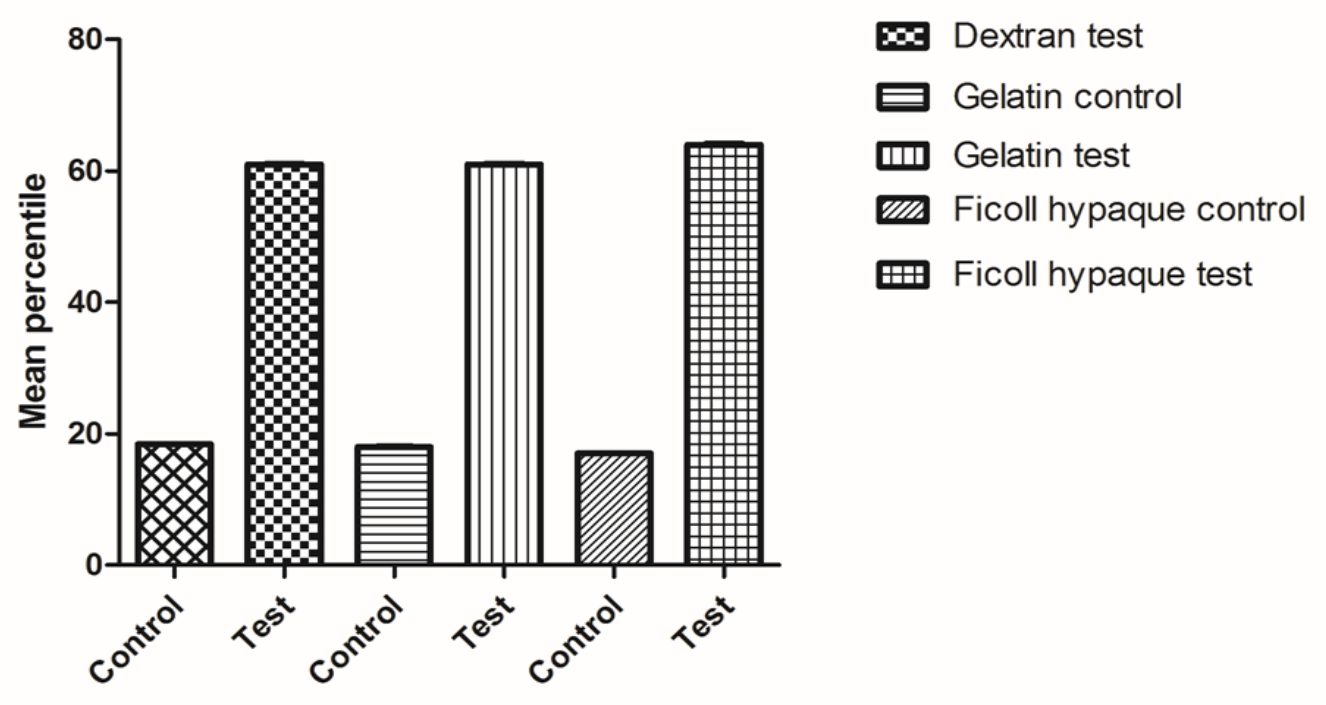

Figure 3: Mean NBT Assay between Test (stimulated) and Control group (unstimulated) 
Discussion: Neutrophil function tests are an integral component of a clinical immunology laboratory and play a decisive role in the diagnosis of several congenital and acquired phagocyte function disorders (1). In addition, these tests are also being used in research to study the immunomodulatory activities of drugs, synthesized compounds and natural products (7-9).

There are several methods that are being applied for the recovery of neutrophils from blood for their functional studies. Among them, the most popular one is the Ficoll-Hypaque density gradient method which separates granulocytes from other blood components. But this method is technically complex and the reagents are expensive. The second method which is based on sedimentation of RBCs using high molecular weight dextran (mol wt 150,000 - 200,000) is also being used by researchers either as an individual procedure or in combination with Ficoll-Hypaque method (2). But dextran sedimentation has the drawback of being capable of stimulation the neutrophils during isolation procedure thus interfering with their functional assessment (10). Hence there is a need for an alternate protocol that is inexpensive, simple to perform and reproducible. Gelatin sedimentation meets with these criteria. Even though described as early as 1971 (11), this method is being adopted for separation of WBCs only in recent years. This procedure has also been found useful for separation of haematpoitec progenitors and stem cells from various sources mainly for their acceptance as a neutral vehicle on the survival and function of cells $(12,13)$.

There are very few studies that have compared various isolation methods to evaluate their effect on cell yield and functional assessment of neutrophils $(14,15)$. Here, we have made an attempt to compare the efficacy of the three methods mentioned earlier in isolation of WBCs and their effect on the results of NBT assay. We found that the cell yield from both dextran and gelatin sedimentation were comparable but the quantity of cells obtained from Ficoll-Hypaque was on the lower side. This appears due to the fact that in Ficoll-Hypaque method, only granulocytes are separated in a layer where as with other two techniques, all WBCs are separated together. There was some variation in the total cell yield from different individuals by the three protocols used as becomes evident from table 1 . However, these differences should not matter because the number of cells isolated from each procedure was sufficient to perform several neutrophil functional assays.

Even though most investigators have used a concentration of $3 \%$ gelatin in their protocols, we found that some preparations were problematic because of cell aggregation. We then tested different concentrations of gelatin for their efficacy that included $2.5 \%, 2 \%, 1.5 \%, 1 \%$ and $0.5 \%$. We found that even with $0.5 \%$, there was no alteration in erythrocyte sedimentation rate and the cell yield was highly satisfactory without any cellular aggregation. This modified protocol was used for isolation of WBCs from all the samples included in our study.

NBT assay is a test used to assess the respiratory burst in an activated phagocyte. Once the cells are stimulated by endotoxin, they are known to phagocytose NBT and also consume large amounts of oxygen for their metabolic activity. During this process, NBT hets converted into insoluble blackish formazan granules which are easily seen in a stained smear under the microscope. In our study, the mean readings of stimulated and unstimulated neutrophils were almost similar with cells isolated from all the three procedures (Figure 3). Even though there were minor variations in few individual samples, the readings were well within normal range. These variations could be seen in samples 1, 5, 12 and 16, 18 and 27. 
It becomes evident from these results that a normal level of unstimulated cells in our study subjects is $18 \%$ with a range of $12 \%-20 \%$. Only in two samples (18 \& 27), the levels of unstimulated cells were higher than expected. This could be due to the presence of a subclinical infection in these subjects resulting in low level of neutrophil stimulation. The levels of stimulated cells in our study were found to be $61 \%$ mean with a range of $48 \%-86 \%$. This is an acceptable result because the minimum number of cells to be stimulated in a NBT assay is around 50\% (16).

\section{Conclusions and Recommendations}

The outcome of our study clearly shows that gelatin method provides high yield of cells with good purity and viability and the results were reproducible. Considering the lower cost of gelatin method in comparison to Ficoll-Hypaque and dextran sedimentation, it can be a viable alternative to be used in a clinical laboratory for isolation of WBCs for performing neutrophil function tests in health and disease.

\section{Acknowledgements}

We would like to thank Director Advanced Research, Rajiv Gandhi University of Health Sciences, Bengaluru for funding this work and Principal, Maratha Mandal's NGH Institute of Dental Sciences and Research Centre for encouraging and permitting us to work at Central Research Laboratory, Belagavi, India.

\section{References}

[1] Kuhns DB. Assessment of Neutrophil function. In Rich RR, Eds Clinical Immunology Principles and Practice, Elsevier, 3rd Ed 2008 Mosby.

[2] Nauseef WM. Isolation of human Neutrophils from venous blood. In Quinn MT, DeLeo FR, Bokoch GM Eds. Neutrophil methods and protocols, Methods in Molecular Biology No 412, 2007, Humana press, 15-20.

[3] Luciano YM, Mantovani B Lysosomal enzyme release from polymorphonuclear leukocytes induced by immune complexes of IgM and IgG. Journal of Imunology 1984, 132, 2015-2020.

[4] Gentle TA, Thompson RA. Neutrophil tests in clinical immunology in Eds Gooi and Chapel H. Clinical immunology: A practical approach. New York, Oxford University press, 1990.

[5] Perutelli P, Catellani S, Scarso L, Cornaglia-Ferraris P, Dini G. Processing of human cord blood by three different procedures for red blood cell depletion and mononuclear cell recovery. Vox Sang 1999, 76, 237-240.

[6] Metcalf JA, Gallin JI, Nauseef WM, Root RK. Laboratory Manual of Neutrophil Function. New York, Ravwn press, 1986.

[7] Kielland LG, Vage RA, Eide GE, Sornes S, Naess A. Antituberculosis drugs and human polymorphonuclear leukocyte functions. Chemother 2011, 57, 339-344.

[8] M. S. Ganachari, Shiv Kumar, K. G. Bhat. Effect of ziziphus jujuba leaves extract on phagocytosis by human neutrophils. Journal of Natural Remedies, 2004, 4, 47-51.

[9] Rahul S. Bhansali, R. K. Yeltiwar, K. G. Bhat. Assessment of peripheral neutrophil functions in patients with localized aggressive periodontitis in Indian population. Journal of Indian Society of Periodontology, 2013, 17, 731-736.

[10] Quach A, Ferrante A. The Application of Dextran Sedimentation as an Initial Step in Neutrophil Purification Promotes Their Stimulation, due to the Presence of Monocytes. Journal of Immunology Research, 2017, 1254792. 
[11] Henson PM The immunologic release of constitients from neutrophil leukocytes I. The role of antibody and complement on nonphagocytosable surfaces or phagocytosable particles. J Immunol 1971; 107: 1535-1546.

[12] Nagler A,Peacock M, Tantoco M, Lamons D, Okarma TB, Okrongly DA. Separation of hematogenic progenitor cells from human umbilical cord. Journal of Hematology \& Oncology. 1993, 2. https://doi.org/10.1089/scd.1.1993.2.243.

[13] Antoniewicz-Papis J, Dzieciatkowska A, Lachert E, Letowska KM, Podstawka U, Apel D et al. Sedimentation as effective method of preliminary isolation of stem cells from cord blood. Reports of Practical Oncology and Radiotherapy, 2001, 6, sup1: s19-s25.

[14] Marchi LF, Sesti-Costa R, Chedraoul-Silva S, Mantovani B. Compariosn of four methods for the isolation of murine blood neutrophils with respect to the release of reactive oxygen and nitrogen species and the expression of immunological receptors. Comparative Clinical Pathology, 2014; 23 : 1469-1476.

[15] Paoliello-Paschoalato AE, Azzolini AECS, Cruz MFC, Marchi LF, Kabeya LM, Donadi EA et al. Isolation of healthy individuals' and rheumatoid arthritis patients' peripheral blood neutrophils by the gelatin and Ficoll-Hypaque methods: Comparative efficiency and impact on the neutrophil oxidative metabolism and Fc $\gamma$ receptor expression. Journal of Immunological Methods, 2014, 412, 70-77.

[16] Wilkinson PC. Neutrophil leucocyte function tests in Thompson RA ed Techniques in clinical immunology, Blackwell Scientific Publications. 2nd ed., 273-293.

\footnotetext{
*Corresponding author.

E-mail address: drkgbhat@yahoo.com
} 